Conclusion: CZP seems to be effective and safe in female patients with uveitis during pregnancy and neonates.

References:

[1] Llorenç $V$ et al. Certolizumab Pegol, a New Anti-TNF-a in the Armamentarium against Ocular Inflammation. Ocul Immunol Inflamm. 2016;24(2):167-72. doi: 10.3109/09273948.2014.967779

[2] Urruticoechea-Arana A et al. Efficacy and safety of biological therapy compared to synthetic immunomodulatory drugs or placebo in the treatment of Behçet's disease associated uveitis: a systematic review. Rheumatol Int. 2019 Jan;39(1):47-58. doi: 10.1007/s00296-018-4193-z

[3] Martín-Varillas JL et al. Successful Optimization of Adalimumab Therapy in Refractory Uveitis Due to Behçet's Disease Ophthalmology. 2018 Sep;125(9):1444-1451. doi: 10.1016/j.ophtha.2018.02.020

[4] Santos-Gómez $M$ et al. The effect of biologic therapy different from infliximab or adalimumab in patients with refractory uveitis due to Behçet's disease: results of a multicentre open-label study. Clin Exp Rheumatol. 2016. SepOct;34(6 Suppl 102): S34-S40

[5] Calvo-Río V et al. Golimumab in refractory uveitis related to spondyloarthritis. Multicenter study of 15 patients.Semin Arthritis Rheum. 2016 Aug;46(1):95101. doi: 10.1016/j.semarthrit.2016.03.002

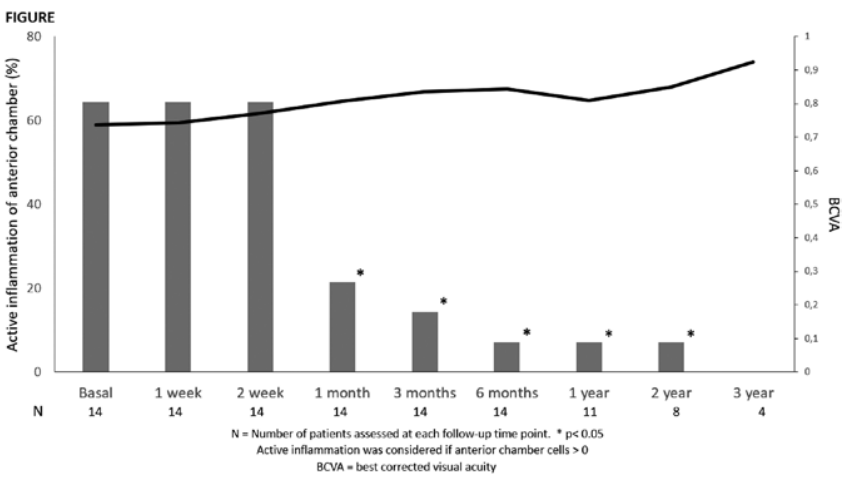

Disclosure of Interests: D. Prieto-Peña: None declared, Monica Calderón-Goercke: None declared, Alfredo Adan: None declared, Lillian Chamorro-López: None declared, Olga Maiz: None declared, JR De Dios-Jiménez Aberásturi: None declared, Raul Veroz Gonzalez: None declared, Soledad Blanco: None declared, José M Santos: None declared, Francisco Navarro: None declared, Adela Gallego: None declared, Senen González-Suárez: None declared, Arantxa Conesa: None declared, Andrea García-Valle: None declared, Miguel Cordero-Coma: None declared, Nieves Pardiñas-Barón: None declared, Rosalía Demetrio-Pablo: None declared, Vanesa Calvo-Río Grant/research support from: MSD and Roche, Speakers bureau: AbbVie, Lilly, Celgene, Grünenthal, UCB Pharma, Victor Manuel Mora-Cuesta: None declared, Santos Castañeda: None declared, J. Luis Hernández: None declared, Miguel A González-Gay Grant/ research support from: Pfizer, Abbvie, MSD, Speakers bureau: Pfizer, Abbvie, MSD, Ricardo Blanco Grant/research support from: AbbVie, MSD, Roche, Consultant of: Abbvie, Eli Lilly, Pfizer, Roche, Bristol-Myers, Janssen, UCB Pharma and MSD, Speakers bureau: Abbvie, Eli Lilly, Pfizer, Roche, Bristol-Myers, Janssen, UCB Pharma. MSD

DOI: 10.1136/annrheumdis-2020-eular.1610

\section{AB1056 SYMPTOMATIC SCLEROSING MESENTERITIS REVEALING ERDHEIM-CHESTER DISEASE: A RARE CONDITION MEDIATED BY BRAF}

J. Razanamahery ${ }^{1}$, S. Humbert ${ }^{2}$, A. Malakhia ${ }^{3}$, J. F. Emile ${ }^{4}$, F. Cohen ${ }^{5}$, J. Haroche ${ }^{5}$, N. Magy-Bertrand ${ }^{1}$. ${ }^{1}$ Besancon University Hospital, Internal Medicine Department, Besancon, France; ${ }^{2}$ Besancon University Hospital, Besancon, France; ${ }^{3}$ Besancon University Hospital, Besancon, France;

${ }^{4}$ Ambroise Paré Hospital, Paris, France; ${ }^{5}$ Internal Medicine Department 2, Paris, France

Background: Sclerosing Mesenteritis (SM) refers to an entire spectrum of digestive inflammatory disorders. Diagnosis is based on imaging showing an increase of fat attenuation displacing bowel loops and is in most cases non-symptomatic. Several conditions (abdominal trauma/surgery, neoplasia, infectious and inflammatory diseases) are responsible for SM (1). Among neoplasia, Erdheim-Chester disease $(E C D)$ is a rare clonal histiocytosis characterized by long bone involvement, peri-nephric fat infiltration and cardio-vascular involvement associated with compatible histology (2). Biopsy is mandatory to confirm tissue infiltration by histiocytes and detect somatic mutation. Almost $80 \%$ of ECDpatients harbor mutation in mitogen activated protein $(M A P)$ kinase pathway especially $B R A F^{V 600 E}$ gene mutation in about $60 \%$ of cases(3). No series of patients presenting both pathologies has been reported. Furthermore, no correlation with $B R A F$ mutation status has been described in patient harboring SM and ECD.

Objectives: To describe the clinical, radiological and mutational status of patients harboring SM and ECD.

Methods: We reviewed the database of patients with histiocytic disorders in Besancon University Hospital. Patient required one abdominal computed tomog raphy showing sclerosing mesenteritis and clinical/histological features of ECD to fulfill the inclusion criteria. All biopsy samples were investigated for mutation of MAP kinase pathway gene.

Results: Four patients suffered from SM and ECD. The median age at the diagnosis of ECD was 68 years old (61-72). All patients described abdomina pain and the mean duration between first symptoms and diagnosis of ECD was 12 months (4-19). The mean CRP level at diagnosis was $40.75 \mathrm{mg} / \mathrm{L}$ (5-117) Two patients were found to have myeloid neoplasms (chronic myelomonocytic leukemia (\#2) and essential thrombocythemia (\#4)) concurrent with ECD diagnosis.

Regarding abdominal computed tomography, all patients had a mesenteric mass associated with hyper-attenuated mesenteric fat and a "fat halo sign". One patient (\#2) had ascites and one had splenomegaly (\#4) but no patient had enlarged lymph nodes. CT also demonstrated peri-nephric fat infiltration ("hairy kidney") (4/4), vascular sheathing of aortic branches (3/4), adrenal hypertrophy (1/4) or ureter dilation (1/4). The mean SUV ${ }_{\max }$ of the mesentery was $7.5(4.1-10.9)$ at diagnosis on $\left({ }^{18} \mathrm{~F}\right)$ - fluorodeoxyglucose-PET. Three patients underwent mesentery fat biopsy and all samples exhibited ECD histology. Regarding mutational status, $75 \%(3 / 4)$ patients had $B R A F^{V 600 E}$ mutation.

After initiation of therapies for ECD (targeted therapies for $3 / 4$ patients), all patients had improvement of digestive symptoms and decreased of SUV $V_{\max }$ on evaluation

${ }^{18}$ FDG-PET during the follow up.

Conclusion: ECD should be investigated in patient with symptomatic SM especially if it is associated with peri-nephric fat infiltration. This condition is rare and might be driven by BRAF gene.

References:

[1] Danford CJ, Lin SC, Wolf JL. Sclerosing Mesenteritis. Am J Gastroenterol. 2019 Jun;114(6):867-73.

[2] Diamond EL, Dagna L, Hyman DM, Cavalli G, Janku F, Estrada-Veras J, et al. Consensus guidelines for the diagnosis and clinical management of Erdheim-Chester disease. Blood. 2014 Jul 24;124(4):483-92.

[3] Haroche J, Cohen-Aubart F, Rollins BJ, Donadieu J, Charlotte F, Idbaih A et al. Histiocytoses: emerging neoplasia behind inflammation. Lancet Oncol. 2017 Feb;18(2):e113-25.

Disclosure of Interests: None declared

DOI: 10.1136/annrheumdis-2020-eular.2447

\section{AB1057 1 SCHNITZLER'S SYNDROME IN THE DIFFERENTIAL DIAGNOSIS OF ADULT STILL'S DISEASE}

\section{S. Salugina ${ }^{1}$, E. Borzova ${ }^{2,3}$, V. Gorodetskiy4, E. Fedorov4. ${ }^{1}$ V.A. Nasonova} Research Institute of Rheumatology, Moscow, Russian Federation; ${ }^{2}$ Department of Clinical Genetics, National Research and Clinical Institute of Pediatrics named after Yuri Veltischevat the Pirogov Russian National Research Medical University, Moscow, Russian Federation; ${ }^{3}$ Department of Dermatology and Venereology, I.M. Sechenov First Moscow State Medical University, Moscow, Russian Federation; ${ }^{1}$ V.A. Nasonova Research Institute of Rheumatology, Moscow, Russian Federation

Background: Schnitzler's syndrome (SchS) and adult onset Still disease (AOSD) are currently considered as multifactorial autoinflammatory diseases (MAIDs) and are classified as systemic inflammation with urticarial rash. Clinical similarities between SchS and AOSD (fever, urticarial rash, arthralgias), increased ESR and CRP and the efficacy of IL-1 inhibitors may lead to the diagnostic delay in SchS pts. Testing for monoclonal gammopathy helps establish the diagnosis in SchS pts but is not routinely used in AOSD pts.

Objectives: to examine demographic, clinical and laboratory characteristics, and the therapy of SchS pts in a single rheumatology center.

Methods: 5 SchS patients (2 females, 3 males), aged 32 to 68 , underwent inpatient and outpatient examinations in the rheumatology center. All pts underwent a standard rheumatology examination, including ESR, CRP and M-gradient. 4 pts underwent genetic testing for mutations in NLRP3, TNFRSF1A genes to exclude MAIDs, such as CAPS and TRAPS.

Results: All pts were initially diagnosed with AOSD. The age at onset ranged between 28 and 66 years. Time to diagnosis varied from 2 to 22 years, being within 4 years in 4 of 5 pts. Patients presented with fever (4), urticarial rash (5) and musculoskeletal manifestations (5) (arthralgia in 3, bone pain in 4). Of 2 pts with serositis one presented with pericarditis and another - with pleuritis. Only 1 demonstrated a sore throat and polyneuropathy of the lower extremities. ESR and CRP were increased in all pts, leukocytosis was noted in 4 (Table 1). The 